\title{
Rumen degradability of concentrate protein, amino acids and starch, and their digestibility in the small intestine of cows*
}

\section{Teresa Żebrowska, Zofia Długołęcka, J.J. Pająk and W. Korczyński}

\author{
The Kielanowski Institute of Animal Physiology and Nutrition, \\ Polish Academy of Sciences \\ 05-110 Jablonna, Poland
}

(Received 4 August 1997; accepted 24 October 1997)

\begin{abstract}
The in situ and mobile nylon bag methods were used to determine the effective degradability of dry matter, crude protein and starch in the rumen and the digestibility of undegraded protein and individual amino acids of various feeds in the small intestine of the cow. The tested feeds included rapeseed oilmeal obtained from six industrial oil mills, soyabean oilmeal, field peas (coloured flowered), peas, field beans, lupin, rye, triticale, wheat, barley, oats, and wheat, rye and barley bran. The chemical and amino acid composition of the rapeseed meals from different sources was similar, and effective protein degradability, calculated assuming $\mathrm{k}=0.05$, ranged from 62 to $70 \%$. The effective protein degradability of oilmeals was lower than in the legume seeds and cereal grains. Among cereals, oats had the highest effective protein degradability $(92 \%)$, the lowest was found in winter barley $(75 \%)$. The disappearance of total $\mathrm{N}$ in the rumen from rapeseed meals was lower than of total amino acids; in the remaining feeds these values were similar. Glutamic acid and arginine were degraded to a greater extent than the remaining amino acids, regardless of the type of feed. Intestinal digestibilities of total $\mathrm{N}$ and amino acids of feeds that were less degradable in the rumen, were higher. Cereal starch was degraded in the rumen to a higher extent than starch in legume seeds.
\end{abstract}

KEY WORDS: rumen, concentrates, amino acid profile, protein, ruminal degradability, intestinal digestibility

* Supported by the State Committee for Scientific Research, Grant No 5 S305 01007 


\section{INTRODUCTION}

In modern nutrition systems for ruminants, the amount of amino acids absorbed in the small intestine is taken as a measure of the amount of amino acids available for further metabolism. Amino acids absorbed in the intestine come from two main sources: bacterial protein synthesized in the rumen and rumen undegraded protein (RUP) of feeds, as well as from endogenous protein secreted into the lumen of the intestinal tract. The true digestibility of bacterial protein in the intestine is relatively stable and ranges between $80-85 \%$ (Vérite and Peyraud, 1989; Hvelplund and Masden, 1990), while true digestibility of RUP of various feeds can vary a great deal (Hvelplund, 1985; Van Straalen et al., 1993; Erasmus et al., 1994; Kusumanti et al., 1996). These differences depend to a considerable degree on the type of feed and the technology used in its production. Intestinal digestibility of RUP also depends on its degree of ruminal degradability (Hvelplund, 1992). The rate of protein degradation in the rumen and the intestinal digestibility of RUP are thus important indicators of the nutritional value of feed protein for ruminants.

The main components of concentrates and concentrate mixtures for ruminants in Poland are cereal grains and bran, rapeseed and soyabean oilmeals (for young animals), legume seeds, chiefly field bean, lupin, field peas. These feeds differ in their chemical composition, and the nutritional value of their protein may vary, depending on the species and variety, as well as production technology.

The aim of this study was to determine the extent and rate of ruminal degradation and intestinal digestibility of protein, individual amino acids and starch of domestic concentrates made with various species and varieties of cereal, legume seeds and by-products from different plants.

\section{MATERIAL AND METHODS}

\section{Animals and nutrition}

The experiment was conducted on 3 cows with body weights of about $500 \mathrm{~kg}$ with fistulas in the rumen and duodenum. They were fed meadow hay to appetite with $1.5 \mathrm{~kg} /$ day mineral-supplemented barley meal, twice daily at $8^{00}$ and $15^{00}$. Water was available ad libitum.

\section{Feeds}

The following feeds were studied: spring and winter barley, spring and winter wheat, rye, triticale, oats, field pea (coloured flowered) cv. Miga and Gamit,. 
peas, field bean cv. Dino and Nadwiślański, narrow-leafed yellow lupin cv. Juno and Wat; all of these feeds were produced by Experimental Station Poświętne (central Poland). Wheat, rye and barley brans were bought from mill Białołęa (near Warsaw), soyabean and rapeseed oilmeals were made by 6 oil mills from various regions of the country.

\section{Dry matter, crude protein and starch degradability}

The degradability of dry matter, protein and starch in the rumen was determined using the in sacco method (Mehrez and Ørskov, 1977). Feeds were ground in a Tecator mill with a sieve pore diameter of $2 \mathrm{~mm}$, and $5 \mathrm{~g}$ samples of feeds were placed in $11 \times 8 \mathrm{~cm}$ nylon bags ( $42 \mu \mathrm{m}$ pore size). The nylon bags containing feeds were incubated in the rumen for $2,4,8,16,24$ and $48 \mathrm{~h}$. For the 2,4 and $8 \mathrm{~h}$ incubation period, 6 bags of each feed were placed in the rumens of 3 cows, for the 24 and $48 \mathrm{~h}$ incubations, 15 bags of each feed were used, and for the $16 \mathrm{~h}$ incubation, 30 bags were inserted in order to obtain sufficient amounts of material to determine intestinal crude protein and amino acid digestibility by the mobile bag method.

After removal from the rumen, the bags were rinsed for $15 \mathrm{~min}$ in an automatic washing machine, dried in a draft drier at $60^{\circ} \mathrm{C}$ for $24 \mathrm{~h}$, then weighed and pooled samples were prepared separately for each cow, duration of incubation and feed. In order to determine the loss of contents due to washing, a , 0 " sample was prepared using $5 \mathrm{~g}$ of each feed in $7 \mathrm{bags}$, which were washed and dried in the same manner as samples after incubation.

\section{Crude protein and amino acids disapperance form the mobile bags}

Intestinal digestibility of protein undegraded in the rumen was determined according to Hvelplund et al. (1992) by the mobile bag method. The material collected after incubation in the rumen for $16 \mathrm{~h}$ was weighed $(0.5 \mathrm{~g})$ and placed in $3 \times 4 \mathrm{~cm}$ nylon bags (pore size $42 \mathrm{~m}$ ); 90 bags were prepared for each feed, 30 per cow. The bags were incubated in a pepsin solution $(100 \mathrm{mg}$ pepsin/L $0.004 \mathrm{M}$ $\mathrm{HCl}$ ) at a temp. of $39^{\circ} \mathrm{C}$ for $2 \mathrm{~h}$. Next, 5 bags per h were introduced through the cannula into the duodenum. The bags were removed from the faeces, washed in a washing machine, dried in a draft drier at $60^{\circ} \mathrm{C}$ for $24 \mathrm{~h}$, weighed, and pooled samples were prepared for analysis. The amino acid composition of the residue after incubation in the rumen and intestine was determined in samples pooled from all of the cows for each feed, on the basis of the total nitrogen content in the individual samples. 


\section{Chemical analyses}

The basic chemical composition of feeds was determined by conventional methods, starch was assayed in cereals, peas and beans by an enzymatic method (AOAC, 1990). Dry matter and total $\mathrm{N}$ were determined in samples incubated in the rumen, and starch was also determined in the residue following incubation in the rumen of cereal and legume feeds. The amino acid composition of feeds, samples after incubation in the rumen and intestine were determined using a Beckman amino acid analyzer. Samples were hydrolyzed in $6 \mathrm{~N} \mathrm{HCl}$ at $110^{\circ}$ for $22 \mathrm{~h}$. Methionine and cystine were determined after preliminary oxidation of samples with performic acid. Tryptophan was not determined.

\section{Calculations}

The effective degradabilities of dry matter, crude protein and starch were computed using NAWAY (Rowet Research Institute) software that is based on the equation developed by McDonald (1981) using a constant outflow rate of $k=0.05$. Degradability of crude protein and amino acids in the rumen was computed from the difference in the content of these components in feeds and samples after $16 \mathrm{~h}$ of incubation in the rumen, while digestibility in the small intestine was calculated as the difference between the content of these components in samples after incubation in the rumen and their content in the mobile bags after passing through the intestine.

\section{RESULTS}

\section{Rapeseed and soyabean oilmeal}

The chemical composition of samples from 6 oil mills was uniform (Table 1). The protein content in dry matter equaled $35.3-36.4 \%$, crude fibre $11.7-15.1 \%$, ether extract $2.7-4.4 \%$. The amino acid composition of these samples was also very similar (Table 2 ).

The rate of degradation in the rumen of dry matter and crude protein in all samples of rapeseed oilmeal was similar, but the samples from oil mill Kruszwica had a tendency to progress more rapidly, while those from oil mill Gdynia more slowly, than the other samples. The effective dry matter degradability ranged from 58.1 to 63.9 , of crude protein from 62.5 (Gdynia) to $70.1 \%$ (Kruszwica) (Table 5). The average effective degradability of dry matter of rapeseed oilmeals was 5 percentage units lower than that of protein. 
TABLE 1

Chemical composition of feeds, \%

\begin{tabular}{|c|c|c|c|c|c|c|c|}
\hline Feeds & $\begin{array}{l}\text { Dry } \\
\text { matter }\end{array}$ & Ash & $\begin{array}{l}\text { Crude } \\
\text { protein }\end{array}$ & $\begin{array}{l}\text { Ether } \\
\text { extract }\end{array}$ & Fibre & $\begin{array}{l}\mathrm{N} \text {-free } \\
\text { extractives }\end{array}$ & Starch \\
\hline \multicolumn{8}{|l|}{ Rapeseed oilmeal } \\
\hline A & 87.8 & 7.7 & 35.6 & 3.1 & 11.7 & 41.9 & \\
\hline B & 89.6 & 7.5 & 36.3 & 4.2 & 14.3 & 37.7 & \\
\hline $\mathrm{C}$ & 89.8 & 7.3 & 35.5 & 3.7 & 13.1 & 40.3 & \\
\hline D & 89.4 & 7.6 & 36.4 & 3.0 & 13.6 & 39.4 & \\
\hline $\mathbf{E}$ & 85.4 & 7.8 & 35.6 & 3.8 & 14.8 & 38.1 & \\
\hline $\mathrm{F}$ & 90.1 & 7.4 & 36.1 & 3.9 & 13.7 & 38.8 & \\
\hline Soyabean oilmeal & 88.1 & 6.4 & 51.7 & 1.2 & 4.9 & 35.5 & 4.3 \\
\hline Wheat bran & 89.2 & 5.3 & 16.1 & 4.6 & 10.9 & 63.1 & 25.7 \\
\hline Rye bran & 87.9 & 4.6 & 14.9 & 3.1 & 6.0 & 71.4 & 31.3 \\
\hline Barley bran & 87.5 & 4.6 & 12.8 & 3.9 & 11.1 & 67.5 & 40.8 \\
\hline \multirow{2}{*}{$\begin{array}{l}\text { Barley, spring Klimek } \\
\text { winter Gil }\end{array}$} & 85.8 & 2.4 & 12.1 & 1.5 & 5.4 & 78.6 & 53.3 \\
\hline & 88.6 & 2.3 & 11.3 & 2.9 & 5.5 & 78.0 & 55.2 \\
\hline Rye, Dańkowskie Złote & 84.9 & 1.8 & 12.5 & 1.9 & 1.9 & 81.9 & 59.6 \\
\hline Triticale, Presto & 85.2 & 1.8 & 15.4 & 1.3 & 2.0 & 79.5 & 64.4 \\
\hline \multirow{2}{*}{$\begin{array}{r}\text { Wheat, spring Henika } \\
\text { winter Kamila }\end{array}$} & 86.2 & 1.9 & 13.8 & 1.7 & 2.2 & 80.4 & 61.9 \\
\hline & 85.6 & 1.6 & 16.1 & 2.1 & 2.5 & 77.7 & 62.3 \\
\hline Oat & 89.2 & 2.2 & 10.5 & 4.5 & 11.9 & 70.7 & 47.3 \\
\hline \multirow{2}{*}{$\begin{array}{l}\text { Field pea, Mige } \\
\text { Gomik }\end{array}$} & 85.8 & 3.6 & 27.7 & 1.1 & 5.9 & 61.7 & 36.2 \\
\hline & 85.5 & 3.5 & 26.3 & 1.7 & 6.6 & 61.9 & 37.9 \\
\hline Pea, Kwestor & 86.9 & 3.5 & 25.9 & 1.2 & 6.3 & 63.1 & 36.4 \\
\hline \multirow{2}{*}{$\begin{array}{l}\text { Field bean, Dino } \\
\text { Nadwiślański }\end{array}$} & 88.1 & 3.7 & 29.9 & 0.6 & 7.1 & 58.7 & 30.5 \\
\hline & 86.6 & 4.0 & 30.4 & 1.1 & 8.7 & 55.8 & 35.1 \\
\hline \multirow{3}{*}{$\begin{array}{l}\text { Lupin, narrow leaved Emir } \\
\text { yellow Juno } \\
\text { white Wat }\end{array}$} & 87.9 & 3.9 & 34.8 & 5.4 & 15.7 & 40.2 & 1.3 \\
\hline & 86.4 & 5.4 & 42.7 & 5.6 & 15.6 & 30.7 & 1.3 \\
\hline & 88.1 & 4.0 & 31.2 & 9.2 & 15.7 & 39.9 & 1.6 \\
\hline
\end{tabular}

A - oil mill - Bielsko Biała

B - oil mill - Brzeg

C - oil mill - Gdynia

D - oil mill - Kruszwica

E - oil mill - Szamotuły

F - oil mill - Warszawa 
TABLE 2

Amino acid (AA) profile (g AA/100 g AA) of rapeseed oilmeals and soyabean oilmeal

\begin{tabular}{|c|c|c|c|c|c|c|c|}
\hline \multirow{2}{*}{$\begin{array}{l}\text { Amino } \\
\text { acids }\end{array}$} & \multicolumn{6}{|c|}{ Rapeseed oilmeals' } & \multirow{2}{*}{ Soyabean oilmeal } \\
\hline & A & B & $\mathrm{C}$ & D & $\mathrm{E}$ & $\mathrm{F}$ & \\
\hline Asp & 8.1 & 8.3 & 8.2 & 8.4 & 8.2 & 8.0 & 11.7 \\
\hline Thr & 4.8 & 5.0 & 4.8 & 4.9 & 5.0 & 4.8 & 3.9 \\
\hline Ser & 4.5 & 4.7 & 4.6 & 4.7 & 4.7 & 4.6 & 5.0 \\
\hline Glu & 20.6 & 20.5 & 19.9 & 19.9 & 20.0 & 20.1 & 20.8 \\
\hline Pro & 6.5 & 6.6 & 6.5 & 6.5 & 6.5 & 6.5 & 5.9 \\
\hline Gly & 5.5 & 5.6 & 5.5 & 5.6 & 5.5 & 5.5 & 4.1 \\
\hline Ala & 4.7 & 4.8 & 4.8 & 4.8 & 4.8 & 4.7 & 4.2 \\
\hline Val & 6.0 & 6.0 & 6.0 & 6.1 & 6.0 & 5.8 & 4.9 \\
\hline Ile & 4.2 & 4.2 & 4.2 & 4.1 & 4.2 & 4.1 & 4.2 \\
\hline Leu & 7.4 & 7.4 & 7.4 & 7.5 & 7.5 & 7.5 & 7.4 \\
\hline Tyr & 3.1 & 3.0 & 3.1 & 3.1 & 3.3 & 3.0 & 3.4 \\
\hline Phe & 4.2 & 4.3 & 4.3 & 4.3 & 4.4 & 4.2 & 5.0 \\
\hline His & 2.7 & 2.8 & 3.1 & 2.9 & 2.9 & 2.9 & 2.6 \\
\hline Lys & 6.0 & 5.8 & 5.6 & 6.0 & 5.8 & 6.1 & 6.3 \\
\hline Arg & 6.3 & 6.1 & 6.3 & 6.5 & 6.4 & 6.3 & 7.4 \\
\hline Cys & 2.7 & 2.5 & 2.7 & 2.4 & 2.4 & 2.7 & 1.6 \\
\hline Met & 2.2 & 2.2 & 2.3 & 2.1 & 2.2 & 2.2 & 1.5 \\
\hline
\end{tabular}

refer to Table 1

TABLE 3

Amino acid (AA) profile (g AA/100 g AA) of cereal grains and cereal brans

\begin{tabular}{|c|c|c|c|c|c|c|c|c|c|c|}
\hline \multirow{2}{*}{$\begin{array}{l}\text { Amino } \\
\text { acids }\end{array}$} & \multicolumn{2}{|c|}{ Barley } & \multirow{2}{*}{$\begin{array}{c}\text { Rye } \\
\text { Dańkowskie } \\
\text { Zlote }\end{array}$} & \multirow[t]{2}{*}{ Triticale } & \multicolumn{2}{|c|}{ Wheat } & \multirow[t]{2}{*}{ Oats } & \multicolumn{3}{|c|}{ Bran } \\
\hline & spring & winter & & & spring & winter & & rye & barley & wheat \\
\hline Asp & 6.4 & 6.3 & 7.4 & 6.0 & 6.1 & 4.9 & 8.6 & 9.3 & 6.8 & 7.6 \\
\hline Thr & 3.7 & 3.8 & 3.5 & 3.1 & 3.2 & 2.9 & 3.8 & 4.1 & 3.5 & 3.7 \\
\hline Ser & 4.4 & 4.5 & 4.4 & 4.7 & 4.4 & 4.5 & 5.0 & 4.6 & 4.4 & 4.7 \\
\hline Glu & 27.5 & 26.5 & 27.9 & 32.0 & 30.7 & 34.7 & 22.3 & 21.0 & 24.7 & 23.9 \\
\hline Pro & 11.0 & 11.0 & 10.8 & 10.2 & 10.2 & 10.4 & 5.5 & 7.5 & 9.8 & 7.3 \\
\hline Gly & 4.1 & 4.4 & 4.3 & 4.1 & 4.0 & 3.8 & 5.2 & 5.5 & 4.5 & 5.5 \\
\hline Ala & 4.1 & 4.3 & 4.1 & 3.8 & 3.8 & 3.4 & 4.9 & 5.2 & 4.6 & 5.0 \\
\hline Val & 5.5 & 5.5 & 5.0 & 4.7 & 5.0 & 4.4 & 5.7 & 5.5 & 5.5 & 5.3 \\
\hline Ile & 3.5 & 3.5 & 3.4 & 3.3 & 3.5 & 3.5 & 3.8 & 3.6 & 3.6 & 3.5 \\
\hline Leu & 7.0 & 7.0 & 6.3 & 6.4 & 6.6 & 6.6 & 7.6 & 6.6 & 7.1 & 6.7 \\
\hline Tyr & 3.1 & 3.3 & 2.7 & 2.8 & 2.8 & 2.7 & 3.4 & 3.0 & 3.2 & 3.1 \\
\hline Phe & 5.2 & 5.0 & 4.8 & 4.6 & 4.8 & 5.0 & 5.4 & 4.5 & 5.2 & 4.5 \\
\hline His & 2.3 & 2.2 & 2.3 & 2.3 & 2.3 & 2.3 & 2.3 & 2.9 & 2.5 & 3.1 \\
\hline Lys & 3.6 & 3.8 & 3.6 & 3.0 & 3.2 & 2.6 & 4.5 & 5.0 & 4.3 & 4.5 \\
\hline Arg & 5.1 & 5.3 & 5.4 & 5.0 & 5.1 & 4.6 & 7.1 & 6.9 & 6.1 & 7.6 \\
\hline Cys & 2.1 & 2.4 & 2.5 & 2.4 & 2.5 & 2.1 & 3.0 & 2.7 & 2.1 & 2.3 \\
\hline Met & 1.5 & 1.5 & 1.7 & 1.6 & 1.7 & 1.3 & 1.7 & 1.8 & 1.7 & 1.7 \\
\hline
\end{tabular}


TABLE 4

Amino acid (AA) profile ( $\mathrm{gAA} / 100 \mathrm{~g} \mathrm{AA}$ ) of peas, field beans and lupins

\begin{tabular}{|c|c|c|c|c|c|c|c|c|}
\hline \multirow{2}{*}{$\begin{array}{l}\text { Amino } \\
\text { acids }\end{array}$} & \multicolumn{2}{|c|}{ Field pea } & \multirow{2}{*}{$\begin{array}{c}\text { Pea } \\
\text { Kwestor }\end{array}$} & \multicolumn{2}{|c|}{ Field bean } & \multicolumn{3}{|c|}{ Lupin } \\
\hline & Mige & Gomik & & Dino & Nadwiślański & Emir & Juno & Wat \\
\hline Asp & 12.2 & 12.4 & 12.4 & 11.5 & 11.5 & 10.3 & 10.0 & 11.1 \\
\hline Thr & 4.0 & 3.9 & 3.9 & 3.8 & 3.7 & 3.7 & 3.3 & 3.9 \\
\hline Ser & 4.9 & 4.9 & 4.9 & 5.3 & 5.1 & 4.9 & 4.9 & 5.6 \\
\hline Glu & 19.2 & 19.2 & 19.5 & 19.5 & 19.5 & 24.7 & 26.3 & 23.8 \\
\hline Pro & 4.3 & 4.3 & 4.5 & 4.6 & 4.7 & 4.3 & 3.9 & 4.3 \\
\hline Gly & 4.5 & 4.5 & 4.5 & 4.3 & 4.4 & 4.4 & 3.8 & 4.0 \\
\hline Ala & 4.5 & 4.5 & 4.4 & 4.1 & 4.2 & 3.5 & 3.1 & 3.5 \\
\hline Val & 5.1 & 5.1 & 5.2 & 4.9 & 5.0 & 4.3 & 3.8 & 4.2 \\
\hline Ile & 4.0 & 4.0 & 4.3 & 4.1 & 4.2 & 3.9 & 3.8 & 3.9 \\
\hline Leu & 7.1 & 7.2 & 7.7 & 7.9 & 7.9 & 7.1 & 7.7 & 7.6 \\
\hline Tyr & 3.2 & 3.2 & 3.5 & 3.4 & 3.4 & 3.5 & 2.8 & 4.5 \\
\hline Phe & 4.6 & 4.5 & 5.2 & 4.5 & 4.5 & 3.9 & 3.8 & 4.1 \\
\hline His & 2.6 & 2.6 & 2.7 & 2.7 & 2.8 & 2.9 & 2.9 & 2.3 \\
\hline Lys & 7.2 & 7.3 & 7.7 & 6.8 & 6.7 & 5.1 & 5.3 & 5.2 \\
\hline Arg & 10.0 & 9.9 & 8.6 & 10.4 & 10.4 & 11.2 & 11.6 & 9.4 \\
\hline Cys & 1.5 & 1.5 & 1.5 & 1.2 & 1.3 & 1.6 & 2.3 & 1.6 \\
\hline Met & 0.9 & 0.9 & 0.9 & 0.7 & 0.7 & 0.7 & 0.6 & 0.7 \\
\hline
\end{tabular}

The disappearance of crude protein during $16 \mathrm{~h}$ of incubation in the rumen averaged $73.3 \%$ and ranged from 66.4 to $79.3 \%$, while that of total amino acids from 68.8 do $80.3 \%$ (Table 9). Among essential amino acids, $70.9-80.8 \%$ of Lys and $72.2-81.0 \%$ of Met disappeared during $16 \mathrm{~h}$ incubation in the rumen. A tendency was observed for His and Arg to undergo a higher degree of degradation than other essential amino acids, and for branched chain amino acids to be degraded more slowly.

No differences were observed in the amino acid composition among samples of rapeseed oilmeal before and after $16 \mathrm{~h}$ of incubation in the rumen, aside from a clearly lower share of glutamic acid and arginine than in feeds, and higher share of threonine in samples following incubation (Table 6).

The effective ruminal degradability of soyabean oilmeal dry matter was 11 percentage units higher than of crude protein. Crude protein was degraded in the rumen to a lesser extent than that of rapeseed meals (Table 5), while the intestinal digestibility of protein and particular amino acids that were not degraded in the rumen was considerably higher than of rapeseed oilmeal (Table 12).

\section{Cereals}

The chemical and amino acid composition of cereal grain and bran is given in Table 1 and 3. The effective degradability of the dry matter of the cereals ranged from 71.2 (oats) to 95.6 (rye). Degradation of bran dry matter was markedly 
TABLE 5

Effective degradability of dry matter (DM), crude protein and starch in the rumen $(\mathrm{k}=0.05)$ and intestinal digestibility of rumen undergraded protein estimated by mobile bags method

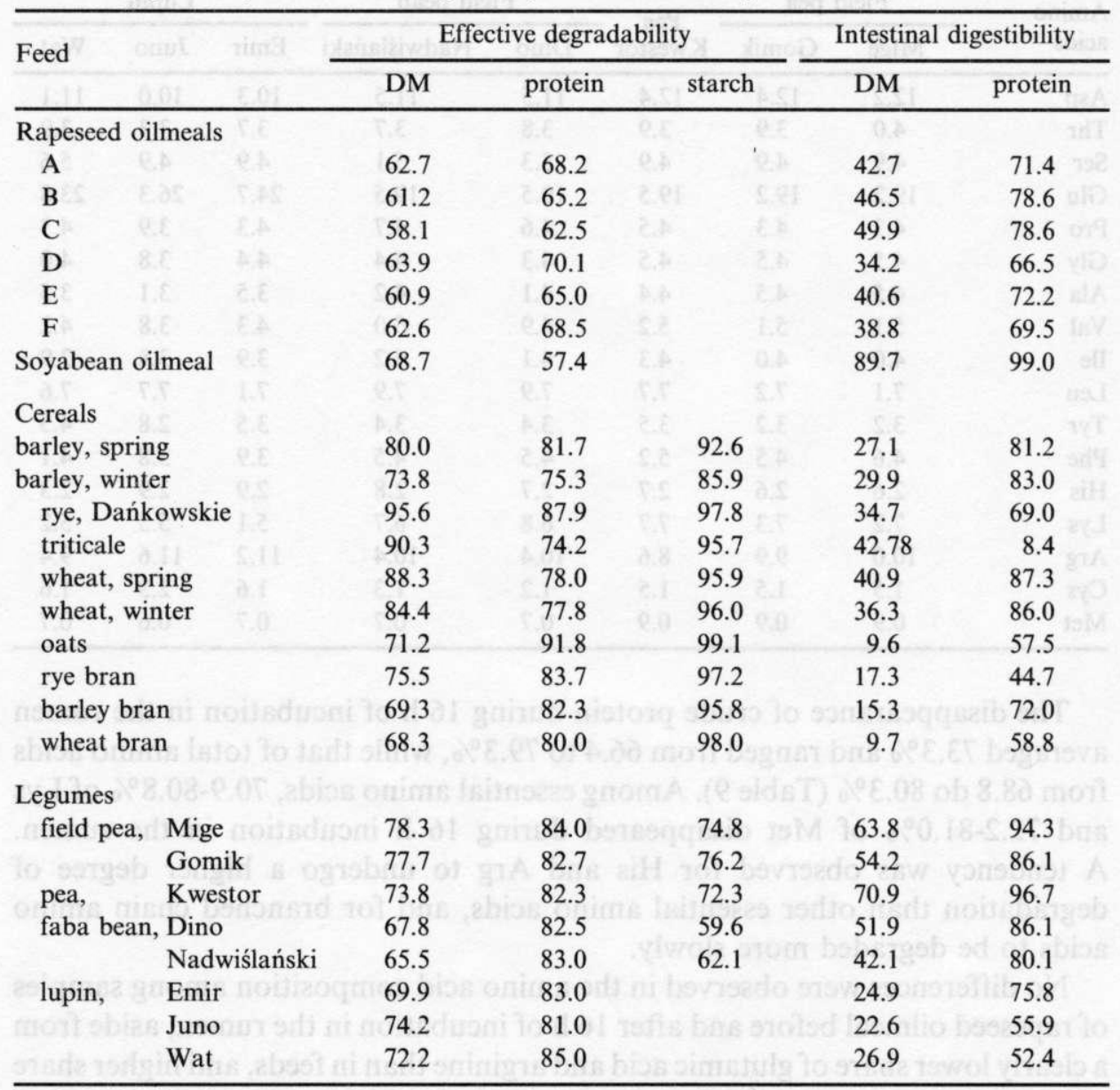

${ }^{1}$ refer to Table 1

lower than of dry matter in the respective grain, but protein was degraded at a similar rate in both bran and grain. Among the studied cereals, the crude protein of oats and rye was characterized by the fastest rate of degradation. Winter barley grain starch was degraded to a lesser degree in the rumen than the starch of the remaining cereals and bran (Table 5).

The degradability of crude protein of cereal grain during $16 \mathrm{~h}$ of incubation ranged from 82.4 (winter barley) to $95.3 \%$ (oats) and was similar to the degradability of total amino acid content (Table 11). 
TABLE 6

Amino acid (AA) profile of residue from rapeseed oilmeal, and soyabean oilmeal after $16 \mathrm{~h}$ incubation in the rumen, $\mathrm{g} \mathrm{AA} / 100 \mathrm{~g} \mathrm{AA}$

\begin{tabular}{|c|c|c|c|c|c|c|c|c|c|}
\hline \multicolumn{2}{|c|}{ Amino acids } & \multicolumn{6}{|c|}{ Rapeseed oilmeals ${ }^{1}$} & \multirow{2}{*}{\multicolumn{2}{|c|}{ Soyabean oilmeal }} \\
\hline 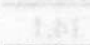 & 045 & A & B & $\mathrm{C}$ & D & $\mathrm{E}$ & $\mathrm{F}$ & & \\
\hline Asp & 2 & 9.5 & 9.3 & 9.2 & 9.6 & 9.4 & 9.5 & 11.6 & \\
\hline Thr & & 5.8 & 5.8 & 5.6 & 5.8 & 5.7 & 5.8 & 4.2 & \\
\hline Ser & & 5.4 & 5.5 & 5.3 & 5.4 & 5.3 & 5.3 & 5.5 & 40 \\
\hline Glu & Es & 14.9 & 16.2 & 16.2 & 15.2 & 15.9 & 15.0 & 8.0 & \\
\hline Pro & $8+4$ & 6.4 & 6.7 & 6.4 & 6.8 & 6.8 & 6.8 & 5.6 & \\
\hline Gly & $2+4$ & 5.7 & 5.6 & 5.6 & 5.6 & 5.5 & 5.6 & 4.3 & \\
\hline Ala & 28 & 5.3 & 5.3 & 5.2 & 5.2 & 5.1 & 5.2 & 4.6 & \\
\hline Val & & 6.6 & 6.4 & 6.4 & 6.7 & 6.6 & 6.7 & 5.1 & \\
\hline Ile & $z^{2}$ & 4.8 & 4.6 & 4.8 & 4.8 & 4.8 & 4.8 & 4.6 & \\
\hline Leu & 0.8 & 8.0 & 8.0 & 8.1 & 7.9 & 8.0 & 7.8 & 8.4 & \\
\hline Tyr & 30 & 3.9 & 3.8 & 3.8 & 3.8 & 3.7 & 3.9 & 3.8 & \\
\hline Phe & & 4.8 & 4.8 & 4.9 & 5.0 & 4.9 & 4.9 & 5.3 & \\
\hline His & 80 & 2.5 & 2.5 & 2.5 & 2.5 & 2.4 & 2.4 & 2.4 & \\
\hline Lys & & 6.1 & 5.6 & 5.7 & 6.0 & 5.9 & 6.0 & 6.2 & \\
\hline Arg & & 5.8 & 5.7 & 5.8 & 5.7 & 5.6 & 5.7 & 6.3 & \\
\hline Cys & & 2.1 & 2.2 & 2.1 & 1.8 & 2.2 & 2.2 & 1.7 & \\
\hline Met & & 2.1 & 2.1 & 2.1 & 2.2 & 2.1 & 2.1 & 1.7 & \\
\hline
\end{tabular}

${ }^{1}$ refer to Table 1

TABELA 7

Amino acid (AA) profile of residue from cereal grains and bran after $16 \mathrm{~h}$ incubation in the rumen, $\mathrm{g} \mathrm{AA} / 100 \mathrm{~g} \mathrm{AA}$

\begin{tabular}{|c|c|c|c|c|c|c|c|c|c|c|c|}
\hline \multirow{2}{*}{\multicolumn{2}{|c|}{ Amino acids }} & \multicolumn{2}{|c|}{ Barley } & \multirow{2}{*}{$\begin{array}{c}\text { Rye } \\
\text { Dańkowskie } \\
\text { Złote }\end{array}$} & \multirow{2}{*}{ Triticale } & \multicolumn{2}{|c|}{ Wheat } & \multirow[t]{2}{*}{ Oats } & \multicolumn{3}{|c|}{ Bran } \\
\hline & & spring & winter & & & spring & winter & & rye & barley & wheat \\
\hline Asp & 8.6 & 7.5 & 6.7 & 9.5 & 7.1 & 6.4 & 6.3 & 10.8 & 10.3 & 7.5 & 9.4 \\
\hline Thr & t & 4.4 & 4.2 & 4.5 & 3.7 & 3.5 & 3.4 & 4.6 & 4.9 & 4.1 & 4.5 \\
\hline Ser & & 5.1 & 5.1 & 5.3 & 4.9 & 5.0 & 5.0 & 5.0 & 5.4 & 4.5 & 5.1 \\
\hline Glu & & 13.0 & 14.5 & 16.0 & 25.0 & 27.3 & 29.7 & 16.6 & 13.2 & 23.4 & 15.7 \\
\hline Pro & & 13.0 & 14.8 & 5.9 & 8.0 & 9.4 & 9.4 & 6.2 & 5.5 & 10.1 & 6.1 \\
\hline Gly & & 4.9 & 4.6 & 6.8 & 4.9 & 4.6 & 4.5 & 6.2 & 8.2 & 4.6 & 7.1 \\
\hline Ala & 582 & 5.1 & 4.6 & 6.1 & 4.8 & 4.3 & 4.2 & 6.6 & 6.4 & 4.8 & 6.1 \\
\hline Val & & 6.5 & 6.2 & 6.3 & 5.6 & 5.3 & 5.1 & 6.2 & 6.1 & 5.6 & 6.0 \\
\hline Ile & & 4.6 & 4.4 & 4.1 & 4.1 & 3.9 & 4.1 & 4.3 & 4.3 & 4.1 & 3.9 \\
\hline Leu & & 8.6 & 8.7 & 8.0 & 7.5 & 7.4 & 4.3 & 8.4 & 7.9 & 7.7 & 7.8 \\
\hline Tyr & के & 3.5 & 5.5 & 329.4 & 2.9 & 2.8 & 2.8 & 1.4 & 3.5 & 2.9 & 3.1 \\
\hline Phe & & 6.7 & 6.9 & 5.2 & 4.9 & 5.1 & 5.4 & 4.8 & 5.4 & 5.9 & 5.1 \\
\hline His & & 2.6 & 2.4 & 2.5 & 2.3 & 2.2 & 2.4 & 2.0 & 2.6 & 1.9 & 2.8 \\
\hline Lys & & 4.0 & 3.5 & 5.1 & 3.7 & 3.5 & 3.3 & 5.0 & 5.1 & 3.8 & 4.7 \\
\hline Arg & & 6.1 & 5.5 & $\begin{array}{r}0.9 \\
\end{array}$ & 6.1 & 5.3 & 6.1 & 6.6 & 6.5 & 5.2 & 7.8 \\
\hline Cys & & 2.1 & 2.0 & 2.5 & 2.1 & 2.1 & 2.1 & 3.1 & 2.7 & 1.9 & 2.7 \\
\hline Met & & 2.2 & 1.9 & 2.0 & 1.9 & 2.0 & 1.9 & 2.2 & 2.2 & 1.7 & 2.3 \\
\hline
\end{tabular}


TABLE 8

Amino acid (AA) profile of residue from legume seeds after $16 \mathrm{~h}$ incubation in the rumen, $\mathrm{gAA} / 100 \mathrm{~g} \mathrm{AA}$

\begin{tabular}{|c|c|c|c|c|c|c|c|c|}
\hline \multirow{2}{*}{ Amino acids } & \multicolumn{2}{|c|}{ Field pea } & \multirow{2}{*}{$\begin{array}{c}\text { Pea } \\
\text { Kwestor }\end{array}$} & \multicolumn{2}{|c|}{ Field bean } & \multicolumn{3}{|c|}{ Lupin } \\
\hline & Mige & Gomik & & Dino & Nadwiślański & Emir & Juno & Wat \\
\hline Asp & 11.8 & 11.8 & 11.8 & 11.5 & 11.5 & 12.6 & 14.0 & 14.1 \\
\hline Thr & 3.7 & 3.7 & 3.5 & 3.8 & 3.8 & 4.2 & 4.8 & 5.0 \\
\hline Ser & 5.1 & 5.2 & 5.0 & 5.3 & 5.3 & 5.7 & 6.3 & 6.9 \\
\hline Glu & 19.7 & 19.0 & 19.5 & 19.2 & 18.9 & 19.1 & 14.0 & 13.4 \\
\hline Pro & 4.6 & 4.9 & 4.8 & 4.9 & 5.0 & 5.0 & 5.3 & 5.7 \\
\hline Gly & 4.3 & 4.6 & 4.0 & 5.0 & 5.4 & 4.4 & 4.8 & 4.5 \\
\hline Ala & 4.4 & 4.5 & 4.3 & 4.2 & 4.3 & 4.1 & 4.6 & 4.1 \\
\hline Val & 5.1 & 5.2 & 5.1 & 5.0 & 5.0 & 5.4 & 6.3 & 6.9 \\
\hline Ile & 4.5 & 4.6 & 4.6 & 4.5 & 4.5 & 4.8 & 5.1 & 4.8 \\
\hline Leu & 8.4 & 8.4 & 8.6 & 8.4 & 8.3 & 7.8 & 8.2 & 7.9 \\
\hline Туг & 3.1 & 3.3 & 3.1 & 3.6 & 3.7 & 3.5 & 3.6 & 4.0 \\
\hline Phe & 5.2 & 5.2 & 5.4 & 4.8 & 4.7 & 5.1 & 6.5 & 5.9 \\
\hline $\mathrm{His}$ & 2.6 & 2.8 & 2.5 & 2.9 & 2.8 & 2.4 & 2.5 & 2.2 \\
\hline Lys & 6.8 & 6.8 & 7.3 & 6.5 & 6.4 & 5.8 & 6.3 & 7.2 \\
\hline Arg & 8.5 & 8.3 & 8.0 & 8.4 & 8.4 & 7.7 & 4.8 & 4.8 \\
\hline Cys & 1.1 & 1.1 & 1.1 & 1.2 & 1.2 & 1.6 & 1.9 & 1.6 \\
\hline Met & 1.0 & 0.8 & 1.1 & 0.9 & 1.0 & 0.9 & 0.8 & 0.9 \\
\hline
\end{tabular}

TABLE 9

Degradability of crude protein and amino acids from rapeseed oilmeals and soyabean oilmeal during $16 \mathrm{~h}$ incubation in the rumen, \%

\begin{tabular}{lcccccccc}
\hline \multirow{2}{*}{ Amino acids } & \multicolumn{7}{c}{ Rapeseed oilmeals' } & \\
\cline { 2 - 7 } & A & B & C & D & E & F & mean & \\
\hline Crude protein & 74.6 & 68.5 & 66.4 & 79.3 & 73.1 & 78.0 & 73.3 & 70.9 \\
Amino acids & & & & & & & & \\
Asp & 73.3 & 65.9 & 67.9 & 78.2 & 73.5 & 75.5 & 72.4 & 71.4 \\
Thr & 73.2 & 64.9 & 67.5 & 77.5 & 73.1 & 75.0 & 71.9 & 68.5 \\
Ser & 73.1 & 64.5 & 67.4 & 78.1 & 73.4 & 76.4 & 72.2 & 68.9 \\
Glu & 84.6 & 76.2 & 77.1 & 85.4 & 81.3 & 85.2 & 81.5 & 74.3 \\
Pro & 78.6 & 69.7 & 72.1 & 80.1 & 75.5 & 78.2 & 75.5 & 72.2 \\
Gly & 77.7 & 69.6 & 71.4 & 80.6 & 76.7 & 79.2 & 75.7 & 69.4 \\
Ala & 75.0 & 67.1 & 69.0 & 79.4 & 75.0 & 77.7 & 73.9 & 68.2 \\
Val & 75.0 & 67.7 & 69.6 & 79.0 & 74.6 & 76.3 & 73.7 & 70.2 \\
Ile & 74.9 & 66.0 & 67.1 & 77.9 & 72.9 & 75.9 & 72.3 & 68.2 \\
Leu & 76.6 & 67.6 & 69.3 & 79.7 & 75.1 & 78.2 & 74.3 & 67.1 \\
Tyr & 72.0 & 62.8 & 66.5 & 77.1 & 72.5 & 73.4 & 70.7 & 67.5 \\
Phe & 74.1 & 65.8 & 67.2 & 78.1 & 73.5 & 76.5 & 72.5 & 69.4 \\
His & 79.1 & 72.5 & 77.7 & 84.2 & 80.1 & 82.3 & 79.3 & 72.6 \\
Lys & 77.9 & 70.9 & 71.8 & 80.8 & 76.3 & 79.3 & 76.0 & 71.7 \\
Arg & 79.4 & 72.2 & 74.0 & 82.9 & 79.1 & 81.4 & 78.2 & 75.4 \\
Cys- & 82.2 & 74.3 & 77.7 & 85.9 & 78.9 & 83.5 & 80.4 & 68.9 \\
Met & 79.8 & 72.2 & 74.1 & 80.8 & 77.1 & 81.0 & 77.3 & 67.2 \\
Mean & 76.4 & 68.8 & 71.0 & 80.3 & 75.8 & 78.5 & 75.2 & 70.1 \\
\hline
\end{tabular}

refer to Table 1 
TABELA 10

Degradability of crude protein and amino acids from legume seeds during $16 \mathrm{~h}$ incubation in the rumen, $\%$

\begin{tabular}{|c|c|c|c|c|c|c|c|c|}
\hline \multirow{2}{*}{ Amino acids } & \multicolumn{2}{|c|}{ Field pea } & \multirow{2}{*}{$\begin{array}{c}\text { Pea } \\
\text { Kwestor }\end{array}$} & \multicolumn{2}{|c|}{ Field bean } & \multicolumn{3}{|c|}{ Lupin } \\
\hline & Mige & Gomik & & Dino & Nadwiślański & Emir & Juno & Wat \\
\hline Crude protein & 87.7 & 87.1 & 83.1 & 89.9 & 82.5 & 93.2 & 96.2 & 95.3 \\
\hline \multicolumn{9}{|l|}{ Amino acids } \\
\hline Asp & 89.6 & 89.5 & 85.7 & 87.6 & 88.0 & 95.8 & 97.6 & 97.1 \\
\hline Thr & 89.8 & 89.5 & 86.3 & 87.6 & 88.0 & 96.1 & 97.5 & 97.2 \\
\hline Ser & 88.8 & 88.5 & 84.5 & 87.3 & 87.7 & 95.9 & 97.8 & 97.2 \\
\hline Glu & 88.9 & 89.1 & 85.0 & 87.8 & 88.4 & 97.3 & 99.1 & 98.7 \\
\hline Pro & 88.3 & 87.4 & 83.8 & 86.6 & 87.1 & 95.9 & 97.6 & 97.0 \\
\hline Gly & 89.8 & 88.8 & 86.5 & 85.5 & 85.2 & 96.5 & 97.8 & 97.5 \\
\hline Ala & 89.5 & 89.2 & 85.3 & 87.2 & 87.7 & 96.0 & 97.5 & 97.3 \\
\hline Val & 89.3 & 88.9 & 85.3 & 87.5 & 88.2 & 95.7 & 97.1 & 96.4 \\
\hline Ile & 87.8 & 87.3 & 84.0 & 86.5 & 87.2 & 95.9 & 97.6 & 97.2 \\
\hline Leu & 87.2 & 87.1 & 83.2 & 86.8 & 87.4 & 96.2 & 98.2 & 97.6 \\
\hline Tyr & 89.5 & 88.8 & 86.6 & 86.9 & 87.1 & 96.5 & 97.8 & 98.0 \\
\hline Phe & 87.7 & 87.5 & 84.7 & 86.8 & 87.6 & 95.6 & 97.1 & 96.7 \\
\hline His & 88.8 & 88.3 & 86.3 & 87.2 & 88.1 & 97.1 & 98.5 & 97.8 \\
\hline Lys & 89.7 & 89.8 & 85.7 & 88.0 & 88.7 & 96.1 & 97.9 & 96.9 \\
\hline Arg & 90.8 & 90.9 & 86.0 & 89.9 & 90.3 & 97.6 & 99.3 & 98.8 \\
\hline Cys & 92.1 & 92.4 & 88.9 & 88.3 & 89.2 & 96.6 & 98.6 & 97.6 \\
\hline Met & 88.4 & 90.4 & 82.6 & 85.3 & 85.4 & 95.4 & 97.7 & 97.1 \\
\hline Mean & 89.2 & 89.0 & 85.3 & 87.2 & 87.7 & 96.2 & 97.9 & 97.4 \\
\hline
\end{tabular}

After $16 \mathrm{~h}$ of incubation in the rumen, the amino acid composition of cereal feeds differed from their initial composition, with the largest differences being noted in the contents of glutamic acid, proline and arginine. The intestinal digestibility of rumen undegraded oat and rye protein was lower than that of the remaining cereals. The digestibility of crude protein of rye bran and wheat bran was characteristically low, 44.7 and $58.8 \%$, respectively. The digestibility of total amino acids was similar to that of crude protein in the respective cereal feeds, while lysine digestibility was 7,10 and 5 , and methionine 8,18 and 10 percentage units higher than the digestibility of total $\mathrm{N}$ of rye, rye and oat bran, respectively (Table 13).

\section{Legume seeds}

The chemical and amino acid composition of different varieties of legume seeds was similar, only Juno lupin was characterized by a higher crude protein content than the remaining lupin varieties (Tables 1 and 4). 
TABLE 11 Degradability of crude protein and amino acids from cereal grains and bran during $16 \mathrm{~h}$ incubation in the rumen, $\%$

\begin{tabular}{|c|c|c|c|c|c|c|c|c|c|c|}
\hline \multirow[b]{2}{*}{ Amino acids } & \multicolumn{2}{|c|}{ Barley } & \multirow{2}{*}{$\begin{array}{c}\text { Rye } \\
\text { Dańkowskie } \\
\text { Złote }\end{array}$} & \multirow[t]{2}{*}{ Triticale } & \multicolumn{2}{|c|}{ Wheat } & \multirow[t]{2}{*}{ Oats } & \multicolumn{3}{|c|}{ Bran } \\
\hline & spring & winter & & & spring & winter & & rye & barley & wheat \\
\hline Crude protein & 87.6 & 82.4 & 91.6 & 87.1 & 88.7 & 87.2 & 95.3 & 90.6 & 86.7 & 85.3 \\
\hline \multicolumn{11}{|l|}{ Amino acids } \\
\hline Asp & 86.7 & 84.5 & 91.5 & 87.6 & 85.1 & 85.5 & 95.0 & 90.9 & 87.0 & 88.1 \\
\hline Thr & 86.6 & 83.3 & 91.6 & 87.4 & 84.5 & 86.6 & 95.3 & 90.0 & 86.6 & 88.6 \\
\hline Ser & 86.8 & 83.3 & 92.2 & 88.9 & 83.9 & 87.6 & 96.1 & 90.3 & 87.8 & 89.9 \\
\hline Glu & 94.6 & 81.6 & 96.2 & 91.8 & 87.3 & 90.3 & 97.1 & 94.8 & 88.9 & 93.8 \\
\hline Pro & 86.5 & 80.2 & 96.4 & 91.7 & 87.0 & 89.7 & 95.5 & 93.9 & 88.0 & 92.0 \\
\hline Gly & 86.5 & 84.5 & 89.7 & 87.2 & 84.2 & 86.4 & 95.2 & 87.7 & 88.1 & 87.6 \\
\hline Ala & 85.7 & 83.9 & 90.5 & 86.6 & 83.7 & 85.8 & 94.7 & 89.9 & 87.4 & 88.1 \\
\hline Val & 86.6 & 83.3 & 91.8 & 87.4 & 84.6 & 87.0 & 90.8 & 90.8 & 88.1 & 89.3 \\
\hline Ile & 85.3 & 81.3 & 92.0 & 87.1 & 84.0 & 86.5 & 95.6 & 90.1 & 87.0 & 89.1 \\
\hline Leu & 85.9 & 82.0 & 91.7 & 87.7 & 83.9 & 92.5 & 95.6 & 90.1 & 87.6 & 89.1 \\
\hline $\mathrm{T}_{\mathrm{yr}}$ & 87.5 & 84.4 & 91.9 & 89.2 & 85.8 & 88.5 & 98.5 & 90.3 & 89.2 & 90.6 \\
\hline Phe & 85.1 & 80.0 & 93.0 & 88.7 & 84.8 & 87.6 & 96.5 & 90.2 & 86.6 & 89.1 \\
\hline His & 87.1 & 84.7 & 92.7 & 88.7 & 86.2 & 87.8 & 96.6 & 92.7 & 90.9 & 91.1 \\
\hline Lys' & 87.7 & 86.0 & 90.9 & 86.7 & 84.3 & 85.5 & 95.6 & 91.5 & 89.5 & 90.2 \\
\hline Arg & 86.2 & 84.5 & 91.5 & 87.0 & 85.0 & 85.1 & 96.3 & 92.3 & 90.1 & 90.3 \\
\hline Cys & 88.9 & 87.4 & 93.5 & 90.6 & 88.0 & 88.5 & 95.9 & 91.8 & 89.6 & 89.3 \\
\hline Met & 83.6 & 81.9 & 91.8 & 87.3 & 83.2 & 84.8 & 95.1 & 89.9 & 88.3 & 87.9 \\
\hline Mean & 86.9 & 83.3 & 92.3 & 88.3 & 85.0 & 87.4 & 95.9 & 91.0 & 88.2 & 89.6 \\
\hline
\end{tabular}

The ruminal degradability of dry matter and crude protein of all legume seeds was similar, although the degradation of field bean protein in the first $4 \mathrm{~h}$ of incubation was slower than of the lupins and peas. The effective degradability of dry matter ranged from 70 to $78 \%$, crude protein from 81 to $85 \%$. Effective degradability of starch in field beans and peas was lower than that of cereal starch (Table 5).

Incubation of feeds in the rumen for $16 \mathrm{~h}$ did not change the proportion of most amino acids in comparison with unincubated samples, with the exception of glutamic acid and arginine, which had a distinctly lower proportion in the samples after incubation (Table 8).

The degradability of crude protein and individual amino acids during $16 \mathrm{~h}$ incubation in the rumen equaled from over $85 \%$ in peas and field beans to over $90 \%$ in lupins (Table 10 ).

Intestinal digestibility of crude protein and the particular amino acids of peas and field beans ranged from 80 to $94 \%$. Crude protein digestibility and that of 
TABELA 12

Intestinal digestibility of rumen-undegraded protein and amino acids of rapeseed oilmeals and soyabean oilmeal, \%

\begin{tabular}{lcccccccc}
\hline \multirow{2}{*}{ Amino acids } & \multicolumn{7}{c}{ Rapeseed oilmeals' } & \\
\cline { 2 - 8 } & A & B & C & D & E & F & mean & \\
\hline Crude protein & 71.4 & 78.6 & 78.6 & 66.5 & 72.2 & 69.5 & 72.8 & 99.0 \\
Amino acids & & & & & & & & \\
Asp & 75.5 & 77.8 & 80.5 & 69.8 & 74.3 & 71.4 & 74.9 & 99.2 \\
Thr & 75.0 & 76.6 & 79.9 & 69.4 & 73.9 & 71.7 & 74.4 & 99.1 \\
Ser & 76.8 & 78.7 & 81.5 & 71.5 & 75.4 & 73.4 & 76.2 & 98.8 \\
Glu & 83.4 & 85.6 & 87.6 & 79.8 & 83.5 & 81.3 & 83.5 & 99.5 \\
Pro & 68.1 & 70.6 & 74.6 & 61.8 & 68.0 & 64.6 & 68.0 & 98.9 \\
Gly & 77.7 & 81.1 & 82.6 & 72.6 & 77.9 & 74.5 & 77.7 & 98.0 \\
Ala & 83.2 & 84.8 & 86.7 & 78.8 & 82.2 & 80.6 & 82.7 & 99.1 \\
Val & 76.9 & 77.7 & 81.3 & 71.2 & 75.6 & 73.4 & 76.0 & 99.1 \\
Ile & 79.9 & 80.3 & 84.0 & 74.1 & 78.6 & 76.6 & 78.9 & 99.3 \\
Leu & 83.8 & 85.1 & 87.3 & 79.4 & 82.8 & 81.0 & 83.2 & 99.3 \\
Tyr & 80.5 & 81.8 & 84.1 & 74.4 & 78.4 & 78.6 & 79.6 & 98.7 \\
Phe & 79.2 & 81.7 & 84.2 & 74.6 & 78.9 & 77.5 & 79.3 & 99.3 \\
His & 81.0 & 84.8 & 84.6 & 76.4 & 79.5 & 79.4 & 81.0 & 98.7 \\
Lys & 78.7 & 80.3 & 82.9 & 73.5 & 77.8 & 76.1 & 78.2 & 99.0 \\
Arg & 81.5 & 85.5 & 86.6 & 79.3 & 82.7 & 81.3 & 82.8 & 99.4 \\
Cys & 67.6 & 72.4 & 73.6 & 67.8 & 67.7 & 64.5 & 68.9 & n.d. \\
Met & 84.3 & 85.5 & 87.5 & 79.4 & 83.1 & 82.6 & 83.7 & n.d. \\
Mean & 78.4 & 80.6 & 82.9 & 73.7 & 77.1 & 75.8 & 78.2 & 99.0 \\
\hline refer to Tableal \\
\hline
\end{tabular}

' refer to Table 1

n.d. - not determined

amino acids of lupins was from 15 to 30 percentage units lower than in the remaining legume seeds (Table 14).

\section{DISCUSSION}

\section{Rumen degradation}

Proteins in the feeds used in the nutrition of ruminants, including those in feed concentrates, vary in their rate of degradation in the rumen resulting from the different chemical characteristics of the protein and the technology used to prepare the feeds. Protein that is undegraded in the rumen and digested in the intestine is a source of supplementary amino acids to ruminal microbial protein. The amount of amino acids available in feed concentrates is particularly important in the nutrition of highly productive animals to ensure coverage of . 
TABELA 13 Intestinal digestibility of rumen - undegraded protein and amino acids of cereal grains and bran, $\%$

\begin{tabular}{|c|c|c|c|c|c|c|c|c|c|c|}
\hline \multirow{2}{*}{$\begin{array}{l}\text { Amino } \\
\text { acids }\end{array}$} & \multicolumn{2}{|c|}{ Barley } & \multirow{2}{*}{$\begin{array}{c}\text { Rye } \\
\text { Dańkowskie } \\
\text { Złote }\end{array}$} & \multirow[t]{2}{*}{ Triticale } & \multicolumn{2}{|c|}{ Wheat } & \multirow[t]{2}{*}{ Oats } & \multicolumn{3}{|c|}{ Bran } \\
\hline & spring & winter & & & spring & winter & & rye & barley & wheat \\
\hline Crude protein & 81.2 & 83.0 & 69.0 & 88.4 & 87.3 & 86.0 & 57.5 & 44.7 & 72.0 & 58.8 \\
\hline \multicolumn{11}{|l|}{ Amino acids } \\
\hline Asp & 74.3 & 74.4 & 71.3 & 84.4 & 84.9 & 83.6 & 59.6 & 49.0 & 68.3 & 55.1 \\
\hline Thr & 80.1 & 82.0 & 70.8 & 85.8 & 87.5 & 86.0 & 57.4 & 47.6 & 72.5 & 54.3 \\
\hline Ser & 80.6 & 82.8 & 72.5 & 87.8 & 89.3 & 88.9 & 57.2 & 48.5 & 74.6 & 54.3 \\
\hline Glu & 82.7 & 94.7 & 83.1 & 95.1 & 96.0 & 95.9 & 69.5 & 60.8 & 89.1 & 71.3 \\
\hline Pro & 91.0 & 92.8 & 74.7 & 92.1 & 93.7 & 93.2 & 49.7 & 46.6 & 85.0 & 59.5 \\
\hline Gly & 74.4 & 76.8 & 60.1 & 81.8 & 81.3 & 78.6 & 46.8 & 36.3 & 64.7 & 41.5 \\
\hline Ala & 76.1 & 76.9 & 72.0 & 85.8 & 85.9 & 83.7 & 58.7 & 50.0 & 69.3 & 54.3 \\
\hline Val & 81.5 & 83.0 & 75.3 & 87.7 & 88.3 & 86.8 & 62.7 & 54.2 & 75.8 & 59.3 \\
\hline Ile & 83.6 & 84.7 & 75.0 & 89.0 & 90.0 & 89.8 & 64.9 & 53.7 & 78.2 & 58.2 \\
\hline Leu & 83.2 & 85.1 & 74.7 & 89.2 & 90.1 & 81.7 & 62.8 & 53.4 & 77.4 & 57.8 \\
\hline Tyr & 82.8 & 84.3 & 69.0 & 86.8 & 87.8 & 87.6 & 26.5 & 40.6 & 88.4 & 43.9 \\
\hline Phe & 83.5 & 85.9 & 73.4 & 88.2 & 89.6 & 90.2 & 65.7 & 51.6 & 83.0 & 55.9 \\
\hline His & 85.5 & 85.8 & 75.6 & 89.6 & 89.8 & 89.7 & 56.2 & 50.0 & 77.1 & 64.9 \\
\hline Lys & 79.0 & 80.4 & 75.9 & 86.7 & 87.3 & 86.0 & 63.5 & 54.4 & 72.6 & 57.9 \\
\hline Arg & 86.2 & 84.3 & 79.2 & 90.1 & 89.4 & 90.1 & 63.7 & 55.7 & 76.4 & 69.3 \\
\hline Cys & 76.5 & 79.2 & 57.2 & 79.5 & 80.9 & 81.3 & 58.1 & 25.8 & 64.4 & 40.0 \\
\hline Met & 82.1 & 83.5 & 77.0 & 89.4 & 90.2 & 89.4 & 68.8 & 62.4 & 74.3 & 64.1 \\
\hline Mean & 81.1 & 83.3 & 72.7 & 87.6 & 88.3 & 87.2 & 58.3 & 49.5 & 76.0 & 56.6 \\
\hline
\end{tabular}

their essential amino acid requirements, particularly of lysine and methionine, the amino acids that most often limit the nutritional value of protein.

The main nutrients of cereal grain and bran were degraded to a considerable degree in the rumen in a short time, and their degradation rates differed only slightly depending on the species and variety. The effective degradability of cereal starch averaged $96 \%$ and was on average 15 percentage units higher than the effective degradability of protein. Among the studied cereals, the degradability of oat dry matter, protein and starch was highest, about $90 \%$, during $2 \mathrm{~h}$ of incubation in the rumen, which confirms the results of Herrer-Saldan et al. (1990). They suggest that the rapid degradation of oat protein is caused by its large proportion of proteins susceptible to ruminal degradation. Oats also contain more easily soluble carbohydrates than other cereals. The rate of starch and protein degradation in barley was slower than in other cereals, and winter barley protein and starch degraded more slowly than those of the spring variety. Lehman et al. (1995) studied various barley varieties and showed considerable differences in degradability among them. It has been suggested (Givens et al., ' 
TABELA 14 Intestinal digestibility of rumen-undegraded protein and amino acids of legume seeds, $\%$

\begin{tabular}{|c|c|c|c|c|c|c|c|c|}
\hline \multirow{2}{*}{$\begin{array}{l}\text { Amino } \\
\text { acids }\end{array}$} & \multicolumn{2}{|c|}{ Field pea } & \multirow{2}{*}{$\begin{array}{c}\text { Pea } \\
\text { Kwestor }\end{array}$} & \multicolumn{2}{|c|}{ Field bean } & \multicolumn{3}{|c|}{ Lupin } \\
\hline & Mige & Gomik & & Dino & Nadwiślański & Emir & Juno & Wat \\
\hline Crude protein & 94.0 & 86.0 & 97.0 & 86.0 & 80.0 & 76.0 & 56.0 & 52.0 \\
\hline \multicolumn{9}{|l|}{ Amino acids } \\
\hline Asp & 93.4 & 86.7 & 94.7 & 88.2 & 83.7 & 79.5 & 56.1 & 52.9 \\
\hline Thr & 92.6 & 83.1 & 94.2 & 86.1 & 80.7 & 80.5 & 58.7 & 55.7 \\
\hline Ser & 93.1 & 85.2 & 94.5 & 87.9 & 83.5 & 74.3 & 55.3 & 49.7 \\
\hline Glu & 95.7 & 90.7 & 96.4 & 92.1 & 89.4 & 91.0 & 72.1 & 71.9 \\
\hline Pro & 92.5 & 84.1 & 94.8 & 87.3 & 83.6 & 80.3 & 58.5 & 55.5 \\
\hline Gly & 90.0 & 76.9 & 93.1 & 73.3 & 64.4 & 79.9 & 57.1 & 55.3 \\
\hline Ala & 92.9 & 85.0 & 94.3 & 87.6 & 82.5 & 80.5 & 60.8 & 59.6 \\
\hline Val & 92.6 & 85.9 & 94.2 & 87.7 & 83.3 & 76.6 & 53.4 & 48.9 \\
\hline Ile & 93.4 & 86.9 & 94.3 & 89.6 & 85.0 & 82.9 & 60.2 & 61.6 \\
\hline Leu & 93.9 & 88.4 & 94.7 & 90.9 & 86.9 & 84.7 & 62.3 & 62.3 \\
\hline Tyr & 92.2 & 84.5 & 92.9 & 81.7 & 73.3 & 78.4 & 57.3 & 57.6 \\
\hline Phe & 93.3 & 87.2 & 94.5 & 89.0 & 84.8 & 81.5 & 58.4 & 57.9 \\
\hline His & 93.6 & 84.8 & 94.8 & 84.4 & 76.5 & 81.4 & 56.1 & 52.7 \\
\hline Lys & 94.6 & 87.0 & 95.6 & 89.6 & 84.8 & 71.5 & 52.5 & 45.3 \\
\hline Arg & 95.7 & 89.7 & 96.2 & 92.3 & 88.8 & 91.2 & 72.1 & 75.2 \\
\hline Cys & 83.0 & 60.5 & 88.9 & 75.6 & 68.2 & 72.1 & 54.2 & 44.9 \\
\hline Met & 91.9 & 78.4 & 94.6 & 83.1 & 79.3 & 81.0 & 70.0 & 73.2 \\
\hline Mean & 92.6 & 83.8 & 94.3 & 94.3 & 81.1 & 80.4 & 59.7 & 57.6 \\
\hline
\end{tabular}

1993) that barley characterized by lower ruminal degradability might be a better feed for ruminants since starch digested in the small intestine supplies more energy. Nocek and Tamminga (1991) showed a positive relationship between the quantity of starch escaping the rumen and entering the intestine and intestinal starch digestion. However, as the quantity of starch entering the intestine increased, starch digestion as a percent of that entering decreased.

The effective degradability of rapeseed oilmeal protein made in various oil mills ranged from 63 to $70 \%$. These results are similar to those reported by Madsen and Hvelplund (1985), equaling 63-77\%, Kendall et al. (1991), 63\% and Dakowski et al. (1996) 70-75\%. The source of the differences found both among the literature data as well as in this study can be the differences in the production technology of rapeseed oilmeal. It is known that excessive heating causes considerable reduction in protein degradation. In the studies of Lindberg et al. (1982), additional heating of oilmeal reduced effective protein degradability to $29 \%$. The experiment by Dakowski et al. (1996) shows that heating meal to 130 , 140 or $150^{\circ} \mathrm{C}$ reduced the effective degradability of protein from about 70 to 57 , 
23 and $14 \%$, respectively. It can be assumed that the differences in the effective degradability of rapeseed oilmeal from different production plants were probably caused by differences in the temperature used to toast the rapeseed.

The results of this study show that the effective degradability of legume seeds and cereal feeds protein (average $82 \%$ ) is significantly higher $(\mathrm{P}<0.01)$ than of rapeseed and soyabean oilmeal (average $65.3 \%$ ); the effective degradability of the dry matter of cereal feeds, mainly of grain, is higher than that of the remaining studied feeds.

The values of effective ruminal degradability of dry matter (72\%) and protein $(83 \%)$ of legume seeds are similar to the values given by Dixon and Hosking (1992). They point to the considerable differences in digestibility and degradability of the dry matter and protein of legume seeds depending on particle size and rumen outflow rate, which means that determining the effective degradability of dry matter and protein in these feeds in sacco is not very precise. In contrast with grains, protein degradability of legume seeds was higher than that of starch. The effective degradability of legume seeds starch was much lower than starch of cereal grain and averaged $74 \%$ for peas and $61 \%$ for field beans. We did not find any data in the literature on the rate of ruminal degradation of legume seeds starch.

The studied feeds differed considerably in the rate of protein degradation during $16 \mathrm{~h}$ of incubation in the rumen. During this time total $\mathrm{N}$ degradability of rapeseed and soyabean meals was $14 \%$ less than in peas and field beans, and $23 \%$ less than in lupin seeds. Among the cereals, total $\mathrm{N}$ of rye and rye bran was degraded to a similar degree as that of lupin, and was higher than of the remaining cereals.

The proportion of the particular amino acids in the protein of feeds and rumen undegraded protein during $16 \mathrm{~h}$ incubation was similar, with the exception of glutamic acid and arginine, of which there was less in the protein remaining after degradation than there was in the feed protein. The clearly higher loss of glutamic acid and arginine than of other amino acids had also been found by other authors (Erasmus et al., 1994; Susmel et al., 1994; Skiba et al., 1996; Südekum and Andree, 1997; Van Straalen et al., 1997). Branched-chain amino acids were degraded slightly more slowly. Differences in the amino acid composition between feed protein and the remainder following incubation in the rumen depend on the type of feed and on contamination of the residue in the bags with nitrogen from microorganisms. Susmel et al. $(1989,1994)$ demonstrated the lack or small effect of incubation in the rumen on the proportion of amino acids in high-protein feeds, while Van Straalen et al. (1997) showed that the share of individual amino acids in the protein of silage and sugar-beet pulp before and after incubation differed considerably, although no such differences were found for soyabean meal. The proportions of amino acids in samples after incubation in. 
the rumen can change depending on contamination with bacterial protein. Erasmus et al. (1994) calculated on the basis of DAPA content that bacterial $\mathrm{N}$ constituted from 2.2 to $5.9 \% \mathrm{~N}$ of total amino acids of rumen undegraded protein from high-protein plant feeds. Taking this factor into account, they showed significant differences in the proportion of Leu, Phe, Lys and Cys in the protein of these feeds before and after incubation in the rumen. In the study of Van Straalen et al. (1997) microbial protein constituted from 0 to $36 \%$ of total nitrogen of amino acids not degraded in the rumen, with the highest values being found for bulk feeds with low protein contents. It can then be assumed that part of the protein found after degradation in the rumen is of microbial origin, but that the share of this protein after incubation of high protein feeds and its effect on the proportion of amino acids is small, which would be in agreement with the suggestions of Varviko and Lindberg (1985). They did show, however, that the results pertaining to the degradability of protein of such starch feeds as cereal grain, can be burdened by an error resulting from the higher contamination by microbial protein than in high-protein feeds.

The differences between ruminal degradability of total $\mathrm{N}$ and the total amino acids of all of the studied feeds were small. This is in agreement with the results of Weakly et al. (1983), Teller et al. (1985) and Rulquin and Vérité (1993), and confirms the suggestion of the latter authors that degradation of total $\mathrm{N}$ in the rumen can be used to estimate the amount of amino acids from the feed entering the small intestine. Analysis of the results of degradation of the particular amino acids in our experiment shows that the degradability of lysine and methionine of rapeseed meals, rye, oats and rye bran was higher than of total $\mathrm{N}$, and that estimating the amounts of these amino acids passing into the intestine on the basis of degradation of total $\mathrm{N}$ in the rumen can give exaggerated results.

\section{Intestinal digestibility of protein and amino acids}

Intestinal digestibility of protein and amino acids comprise digestibility in the small and large intestines as the mobile bags were recovered from faeces. This is in agreement with the generally accepted method, since it has been shown (Hvelplund, 1985; Vanhatalo, 1995) that feed protein is only slightly digested in the large intestine and this does not have a significant effect on intestinal digestibility.

The decrease in total $\mathrm{N}$ and total amino acids in the intestine from rumen undegraded protein of the studied feeds was similar, with the exception of rapeseed oilmeal, Dino faba beans and Emir lupin, in which the decline in total amino acids was greater than in the degradability of total $\mathrm{N}$. This may show that in these feeds, there are more non-protein nitrogenous compounds that do not undergo degradation in the rumen and are not digested in the intestine. 
Intestinal digestibility of rumen undegraded rapeseed oilmeal protein averaged $72 \%$, and of lysine and methionine, the amino acids considered limiting for cows, 78 and $84 \%$, respectively. These values are similar to the data given by other authors (Hvelplund, 1985; De Boer, 1987; Dakowski et al., 1996). Rapeseed oilmeal protein is rich in methionine and with its low degradation rate in the rumen and high digestibility of methionine in the small intestine, can be a good source of this amino acid for ruminants. The intestinal digestibility of rumen undegraded protein and of lysine and methionine of soyabean meal was higher than in other feeds and equaled $99 \%$, a value similar to that given by van Straalen et al. (1987). The intestinal degestibility of protein and amino acids of various varieties of field peas, field bean, barley and wheat was similar. Feeds for which rumen degradability of protein and amino acids was the highest (oats, rye, lupin) were characterized by a low, with the exception of rapeseed meal, Dino faba beans and Emir lupin, digestibility of these components in the intestine.

Assuming that total $\mathrm{N}$ and amino acids remaining after $16 \mathrm{~h}$ of incubation in the rumen enter to the duodenum, and that the disappearance from the mobile bag represents the amount absorbed in the small intestine, the amount of total $\mathrm{N}$ and essential and nonessential amino acids that was absorbed from the feed in the intestine was computed. The calculations show that 20 and $29 \%$ of total N, 20 and $30 \%$ essential amino acids (EAA) and 18 and $30 \%$ nonessential amino acids (NEAA) of rapeseed and soyabean meal, respectively, was absorbed. Of the legume seeds, from 3 (lupin) to $16 \%$ of total $\mathrm{N}$ (peas), $2-14 \%$ EAA and $2-12 \%$ NEAA was absorbed in the intestine. Among the cereal feeds, the most EAA $(14 \%)$ and NEAA $(13 \%)$ was absorbed in the small intestine from winter barley, the least from rye and oats, 6 and $2 \%$, respectively. This shows that the protein of lupins, rye and oat grains are poor sources of amino acids for ruminants.

\section{REFERENCES}

Association of Official Analytical Chemists, 1990. Official Methods of Analysis. 15th edition, Assoc. Offic. Anal. Chem., Washington, DC

Dakowski P., Weisbjerg M.R., Hvelplund T., 1996. The effect of temperature during processing of rape seed meal on amino acid degradation in the rumen and digestion in the intestine. Anim. Feed Sci. Technol. 58, 213-226

DeBoer G., Murphy J.J., Kennelly J.J., 1987. Mobile nylon bag for estimating undegradable protein. J. Dairy Sci. 70, 977-982

Dixon M., Hosking B.J., 1992. Nutritional value of grain legumes for ruminants. Nutr. Res. Rev. 5, $19-43$

Erasmus L.J., Botha P.M., Cruywagen C.W., 1994. Amino acid profile and intestinal digestibility in dairy cows of rumen-undegradable protein from various feedstuffs. J. Dairy Sci. 77, 541-551

Frydrych Z., 1992. Intestinal digestibility of rumen undegraded protein of various feeds as estimated by the mobile bag technique. Anim. Feed Sci. Technol. 37, 161-172 
Givens D.J., Clark P., Jacklin D., Moss A.R., Savery C., 1993. Nutritional aspects of cereals, cereal grain by-products and cereal straw for ruminants. HGCA Research Review, No 24; 1-180 Home-Grown Cereals Authority, Hamlyn House, Highgate Hill, London

Herrera-Saldana R.E., Huber J.T., Poope M.H., 1990. Dry matter, crude protein, and starch degradability of five cereal grains. J. Dairy Sci. 73, 2386-2393

Hvelplund T., 1985. Digestibility of rumen microbial protein estimated in the small intestine of sheep or by in sacco procedure. Acta Agric. Scand., Suppl. 25, 132-144

Hvelplund T., Madsen J., 1990. A study of the quantitative nitrogen metabolism in the gastrointestinal tract, and the resultant new protein evaluation system for ruminants. The AAT-PBV System. Thesis, Institute of Animal Science, The Royal Veterinary and Agricultural University, Copenhagen, pp. 275

Hvelplund T., Weisbjerg M.R., Andersen L.S., 1992. Estimation of the true digestibility of rumen undegraded dietary protein in the small intestine of ruminants by the mobile bag technique. Acta Agric. Scand., Sect. A., Anim. Sci. 42, 34-39

Kendall E.M., Ingalls J.R., Boila R.J., 1991. Variability in the rumen degradability and postruminal digestion of the dry matter, nitrogen and amino acids of canola meal. Can.J. Anim. Sci. 71, 739-754

Kusumanti E., Weisbjerg M.R., Hvelplund T., 1996. A comparison between protein disappearance from the mobile bag and acid detergent solubility of nitrogen as estimates of protein digestibility in ruminants. J. Anim. Feed Sci. 5, 337-345

Lehman K.B., Okine E.K., Mathison G.W., Helm J., 1995. In situ degradabilities of barley grain cultivars. Can. J. Anim. Sci. 75, 485-487

Lindberg J.E., Soliman H.S., Sanne S., 1982. A study of the rumen degradation of untreated and heat-treated rapeseed meal and of whole rape seed including a comparison between two nylon bag techniques. Swed. J. Agric. Res. 12, 83-88

Madsen J., Hvelplund T., 1985. Protein degradation in the rumen. A comparison between in vivo, nylon bag, in vitro and buffer measurements. Acta Agric. Scand., Suppl. 25, 103-124

Mehrez A.Z., Ørskov E.R., 1977. A study of the artificial fibre bag technique for determining the digestibility of feeds in the rumen. J. Agric. Sci., Camb. 88, 645-650

McDonald I.M., 1981. A revised model for the estimation of protein degradability in rumen. J. Agric. Sci., Camb. 96, 251-252

Nocek J.E., Tamminga S., 1991. Site of digestion of starch in the gastrointestinal tract of dairy cows and its effect on milk yield and composition. J. Dairy Sci. 74, 3598-3629

Rulquin H., Vérité R., 1993. Amino acid nutrition of dairy cows: productive effects and animal requirements. In C.P. Garnsworthy, D.J.A. Cole (Editors). Recent advances in animal nutrition, pp. 55-79

Skiba B., Weisbjerg M.R., Hvelplund T., 1996. Rumen and total intestinal tract digestibility of protein and amino acids from different roughages, detcrmined in situ. J. Anim. Feed Sci. 5, 347-363

Susmel P., Antongiovanni M., Stefanon B., Mills C.R., Hindle V.A., van Vuuren A.M., 1994. Biological and chemical assessment of feed proteins before and after rumen exposure. Anim. Feed Sci. Technol. 49, 119-132

Susmel P., Stefanon B., Milis C.R., Candido M., 1989. Change in amino acid composition of different protein sources after rumen incubation. Anim. Prod. 49, 375-383

Südekum K.-H., Andree H., 1997. Evaluation of three rape seed commodities in the rumen of steers. 1. Degradation of dry matter and crude protein and disappearance of amino acids in situ. J. Anim. Feed Sci. 6, 23-40

Straalen van W.M., Dooper F.M.H., Antoniewicz A.M., Kosmala I., Van Vuuren A.M., 1993. Intestinal digestibility in dairy cows of protein from grass and clover measured with mobile nylon bag and other methods. J. Dairy Sci. 76, 2970-2981 
Straalen van W.M., Ondinga J.J., Mostert W., 1997. Digestion of feed amino acids in the rumen and small intestine of dairy cows measured with nylon-bag techniques. Brit. J. Nutr. 77, 83-97

Teller E., Godean J.M., Van Nevel C.J., Demeyer D.J., 1985. Comparative in vitro and in vivo evaluation of protein degradability in the rumen using soyabean meal and Pruteen. J. Anim. Physiol. Anim. Nutr. 54, 121-130

Vanhatalo A., 1995. Assessment of intestinal feed nitrogen digestibility in ruminants by the mobile-bag method. Dissertation. Agricultural Research Centre of Finland. Institute of Animal Production, pp. 124

Vavrikko T., Lindberg J.E., 1985. Microbial nitrogen in nylon bag residues quantified by feed ${ }^{15} \mathrm{~N}$ dilution. Brit. J. Nutr. 54, 473-481

Vérité R., Peyraud J.L., 1989. Protein: The PDI System. In: R. Jarrige (Editor). Ruminant Nutrition, INRA, pp.33-47

Weakley D.C., Stern M.D., Satter L.D., 1983. Factors affecting disappearance of feedstuffs from bags suspended in the rumen. J.Anim. Sci. 56, 493-507

\section{STRESZCZENIE}

Rozklad w żwaczu bialka, aminokwasów i skrobi pasz treściwych oraz ich strawność w jelicie cienkim krów

Oznaczono efektywny rozkład suchej masy, białka ogólnego i skrobi w żwaczu (in situ) oraz strawnośc nierozłożonego w żwaczu białka i poszczególnych aminokwasów różnych pasz w jelicie cienkim (mobile bags) krów. Badaniom poddano poekstrakcyjną śrutę rzepakową wyprodukowaną w sześciu zakładach przemysłu tłuszczowego, poekstrakcyjną śrutę sojową, nasiona peluszki, grochu, bobiku, łubinu, ziarna żyta, pszenżyta, pszenicy, jęczmienia i owsa, otręby pszenne, żytnie i jęczmienne. Skład chemiczny i aminokwasowy poekstrakcyjnych śrut rzepakowych byl podobny, a efektywny rozklad białka w żwac7u, obliczony przy $\mathrm{k}=0,05$, wynosił od 62 do $70 \%$. Efektywny rozkład białka śrut poekstrakcyjnych byl mniejszy niż nasion roślin strączkowych i pasz zbożowych. Spośród zbóż efektywny rozkład białka był najwyższy dla owsa $(92 \%)$, a najniższy dla jęczmienia ozimego (75\%). Ubytek w żwaczu azotu ogólnego po 16 godzinnej inkubacji śrut rzepakowych był mniejszy niź sumy aminokwasów, podczas gdy wartości te u pozostałych pasz. były podobne. Kwas glutaminowy i arginina ulegały degradacji w żwaczu w większym stopniu niż pozostałe aminokwasy, niezaleźnie od rodzaju paszy. Strawność w jelicie cienkim białka ogólnego $j$ aminokwasów pasz o mniejszej degradacji w żwaczu była większa. Skrobia zbóż ulegała rozkładowi w żwaczu w większym stopniu niż skrobia nasion roślin strączkowych. 